\title{
Animation, branding and authorship in the construction of the 'anti-Disney' ethos: Hayao Miyazaki's works and persona through Disney film criticism
}

\section{Manuel Hernández-Pérez}

University of Hull, School of Drama, Music and Screen

\section{Introduction}

I have something that I want you to learn here. This is the Walt Disney Studio. If you're thinking of making a name for yourself, then you'd better get the hell out of here now, because the one thing we are selling here is 'Walt Disney.' Not because it's me. But because that's the name for the Studio.

Walt Disney, quoted in Anderson (2005:104)

For general audiences, 'Disney' is synonymous with family entertainment, and the family unit itself is also traditionally identified with animation. However, Disney is not only the name of one of the most important content creators in film history but also one of the most emblematic global entertainment trademarks. The company obtained a total consolidated revenue of \$52.4 billion in 2015 (The Walt Disney Company, 2015). After consolidating its strategy for the incorporation of other characters and franchises, such as Lucasfilm and Marvel (De la Merced, 2012), Disney has become the leading corporate entertainment content producer. 
As a term, Disney is of a great importance within media and film scholarship; through decades, it has acquired an aura that is seemingly admired and demonised in equal measure. Key paradigms in cultural and film criticism such as the theories of adaptation and auteurism, also known as 'author theory', have contributed to this debate. Precisely, the aim of this article is to map out these critical approaches to the figure of Walt Disney in order to portray modern applications of the author theory to animation. As a case study, this essay will examine the figure of Hayao Miyazaki, leading filmmaker of Studio Ghibli, and his work. The advanced age of the filmmaker (born in 1941) and the recent dismantling of the Studio Ghibli production department (now limited to some minor productions such as the exclusive short films screened at Ghibli Museum in Mitaka) allow a certain sense of closure. Moreover, one could argue that Miyazaki has in many ways reached the zenith of his career in terms of popularity, critical influence, and commercial success after receiving the Honorary Academy Award in February 2015. Lastly, among other modern Japanese filmmakers, there is a tendency within film criticism and media studies to highlight Hayao Miyazaki as a fitting comparison with the Walt Disney figure.

Both film critics and media scholars typically compare the works of Disney and Miyazaki using the technical quality of their animation as the main criterion. This is one way to introduce Miyazaki's figure to new (Western) audiences, namely as the "Japanese Walt Disney" (Jolin, 2011) or the "new Disney of Japan" (Hu, 2010: 116), as 
well as other Disney-based labels. This portrait is based on his personal authority as head producer as well as the relevance of Studio Ghibli within the animation industry. $\mathrm{Hu}$ (2010: 118) defines Ghibli movies as "high-budget productions" and organised in order to offer "consistent output and quality". Scholars also establish a similarity based on a stylistic approach, pointing out that Miyazaki's (hyper)realism can be compared to Disney's Golden Era (Wells, 2002:17).

The frequent use of Disney references may be an attempt to evoke the uniqueness or singularity of Miyazaki as a film figure, by comparing him with the most well known name within the animation medium. Yet the use of the Disney label appears to attract some controversy, causing the opposite effect. Some scholars find such comparison with the American animator inappropriate (McCarthy, 2000:10; Moist \& Bartholow, 2007:30), because it obfuscates the Miyazaki's uniqueness. For them, the use of a 'Disney' label is merely a superficial way of understanding his contributions as an auteur.

This article aims to examine the current state of author theories in the field of animation, making use of the Walt Disney figure through a review of different forms of criticism. These frameworks can be reapplied in a parallel criticism of Hayao Miyazaki's works and figure. Conversely, a comparison with Disney can also be set in antithetical terms, by establishing a relationship of opposition between the Japanese and 
American authors, based on narrative, stylistic and ideological differences. These contrasts and incompatibilities eventually will take shape as the mythical construction or the persona of the 'Anti-Disney'. By comparison or through opposition, the multiple references to Miyazaki ('Japanese Disney', 'The Asian Disney', etc.) with either interpretation reveal a common analytical perspective. This approach is based categorically on the designation of a certain uniqueness, a singular signature founded on the concept of 'auteur'.

However, as can be seen through the figure of Walt Disney, the concept of 'author' may have alternative meanings, such as aspects that go beyond individual identity to become regarded as the product of a collective or even corporate signature. A deeper examination of these aspects leads to the conclusion that the use of 'Disney' as an adjective_-along with similar labels such as the 'Japanese Walt Disney' or 'antiDisney' - in criticism on Miyazaki films, rests on an outdated notion of authorship. This classical version of the auteur theory may not suffice for the analysis of global cinematic trends such as transmedia authorship or transnational influences, both relevant factors in the emergence of the Hayao Miyazaki and Walt Disney figures. One must note that the aim of this article is to defend the comprehensive use of auterism as an approach for the study of media texts, even while highlighting some studied disadvantages. 


\section{Animation studies and the author theory}

The figure of the film author has been recognised since early theoretical approaches to the cinema such as autorenfilm in Germany or the French film d' art (Hayward, 2013: 27). Yet the author function was not recognised in film theory until the 1950's. Initially, 'author theory' was developed by the influential writers of Cahiers Du Cinema and redefined 'authors' according to the aesthetic value and the narrative modes of their work. Iconic mainstream authors who were identified with the impersonal narrative devices of industry and were thus denied the status of 'auteur' could now take their place in the film pantheon for the first time. Taking the work of Hitchcock as one relevant example of auteurism, critics noted how 'form does not embellish content, (but) it creates it' (Rohmer \& Chabrol, 1979: 152). As a consequence of the controversy sparked by the 'politique des auteurs', the idea that an author's stylistic signature could be observed in a film gained acceptance, despite the inevitable imprint of mechanisms such as adaptation or genre production, both of them traditionally considered as natural enemies of the auteur theory.

Film scholarship has already described the problems with auteur approaches extensively. Nevertheless, it may be necessary to examine the peculiarities of animation industries in relation to those problems with authorship and auteurism. 
Authorship is an exercise of style that creates an individual identity, which eventually can affect the understanding of the film itself as an act of communication. However, the assumption of consistency in terms of the author's vision or style may clash with the collaborative nature of cinema. Multiple authorship is assumed within film theories, but auteurs' perspectives emphasise the role of the director over other professionals involved in production. In the past, other roles in the industry have been regarded as exercises of authorial signatures, most notably in discussions of the filmic producer or 'producer auteur' (Bernstein, 2008). However, this role is considered not as a creative agent but rather as a creative director, whose functions are to gather and coordinate the talents of a team according to his or her personal vision. Necessarily, when the producer's vision takes precedence over that of the filmmaker, we can only speak of single authorship. This is also the case for animation cinema, in which producers sometimes establish a much more recognizable stylistic identity. On some occasions, there is a kind of patronage by producers-filmmakers for promising new entrants to the industry, in which case the recognition of new cinema is attributed to the 'patron studio' before the individuals style become established and known. This was the case for Robert Zemeckis' films, which were promoted as Spielberg's productions. In the animation world it is also common to use the prestige of brands and producers in order to ease the distribution of an unfamiliar product among general audiences. This is true in the case of John Lasseter's signature, which is prestigious as either a producer or a 
filmmaker; his name has served as patronage for younger filmmakers such as Brad Bird, and more significantly, for international figures such as Hayao Miyazaki (McCarthy, 1999).

The wide forms of collaboration are recognisable not only in the textual attributes of cinema production but also in extra-textual or 'paratextual features' (Carringer, 2001; Wells, 2002: 76), all of them surrounding the pivotal figure of the filmmaker. This is also true for promotional texts, as the construction of 'identity' requires not only some stylistic consistency but also external recognition. As has been noted in auteurism, 'the auteur theory serves as a convenient figure of speech' (Sarris, 1963: 30). Any judgment about the work is only made after considering available information on the creator. In auterism the textual analysis is guided by paratextual elements. Critics generally invest greater effort in collecting personal information about the author than in performing a proper (textual) analysis of the work itself. This may be due to the tendency of authorship speech to be consistent and continuously reinforced by other critics and historian analysis. Moreover, critics and scholars show a certain 'anxiety' by delaying the important point of the analysis — namely, the author's work, while focusing more on other (para)textual analysis.

In short, the main problematic behind the 'author' seems rooted in the critic's preference for cultural over textual analysis. In fact, as this essay points out, authorship 
may be more a paratextual than textual phenomenon, taking shape in several forms of commentary: promotional texts (trailers, posters, interviews and reports), academic research, cultural criticism and even merchandising products. This overuse of paratext in film analysis reveals two relevant handicaps in the use of auteurism as a tool of analysis. First, it shows a clear interdependence between current forms of both cultural and textual analysis. Second, the proliferation of paratexts and their diverse typologies places greater importance on the scholar over the filmmaker, just as critics tend to star in auteurism analysis. Other challenges may affect the re-conceptualisation of authorship in relation to the animated medium.

Firstly, modern animation films' introduction and the elevation of a new kind of filmmaker who incorporates executive production's roles, supervises creative aspects and finally becomes an almighty creator, is pivotal. This role emerges over a wide spectrum of media, from modest animation shorts to heavily CGI productions and even other multi-platform franchise tie-in products. In fact, it is precisely in the field of animation that we can begin to establish a history of transmedia authors.

The classical animation framework, modelled after Disney, has been a determinant for this. Not only relevant figures such as Max Fleischer (1883-1972), Walt Disney (19011966) or George Lucas (1944), but also digital technologies and the subsequent hybridization of filmic languages have largely contributed to the consolidation of this 
role. Now more than ever, the boundaries between animation and modern cinema, with its digital compositing techniques and special effects, are diffuse. This has led to a reconsideration of animation and film definitions. For example, a new theoretical framework (Martinez, 2015) treats both film products representing the movement of an artificial way (positive criterion), and works that avoid a correspondence with real-time movement rate of change (negative criterion), as animations. These new restrictions on the definition of animation do not change the fact that animation is a narrative act and, as such, the product of authorship. This authorial act can be represented through various media simultaneously, including animation; it is therefore more inclusive to address transmedia authorship.

The second challenge is intrinsically related to the rise of transmedia authors. For a definition of the transmedia author, one must designate figures that capture certain stylistic or narrative qualities ('individual signatures') and at the same time present this authorial identity in a recognizable way, through the creation and promotion of that signature. This may imply the creation of a persona or the ability to transfer these qualities to a corporate authorial identity or 'brand'.

Marking a turning point in the history of cinema, Disney is the main example of a chief producer who is perceived in nearly all of his production components, such as character design, musical score composition and even aspects as subtle as colour palette. The 
definition of certain Disney style may be implicit but it is not a coincidence that the man's 'personal signature' has been so used in promotion and development, as it illustrates the greatest achievement of the filmmaker, which is the creation of the 'Disney' brand. This is precisely why understanding Walt Disney's work is so relevant to the study of authorship theory and to other animators' legacy.

\section{'Disney' as model for animation criticism}

As mentioned previously, one of the most common features of author theories is the critical relevance that biographical traits acquire in textual analysis. The logic of applying the author's biographical traits to textual analysis is often repeated and extrapolated to the corporate level, such that the results fall somewhere between political economy and critical perspectives. They present extended data on the company, such as its acquisitions and mergers, sales, marketing strategies, etc., but this data is always intended to be a tool for narrative analysis. This approach can be similar to that of auteurism as it relies on the agent's background - its 'corporate biography'before pointing out its current role as an agent of the process. Thus, the author now becomes an impersonal entity or 'mega-corporation'.

Walt Disney (1901-1966) is arguably one of the most important creators in the history of cinema. Disney's personality and film ethos are well-established images that have 
been extended onto analysis of his legacy. Even decades after his death, Disney productions are still considered examples of an entire textual corpus, as if they were signed by the man himself. He is seen as 'the key pioneering figure in the creation of the art, commerce and industry of animation' (Wells, 2002: 77). Due to the relevance of the Disney corporation, it may be necessary to question how this overgeneralization affects thousands of projects realised by different authors among dispersed media. For example, can the products of the cinematic franchise Tron (1982-2010) continue to be considered part of the Disney textual corpus, in any sense? How are Disney princess dolls or modern reformulations of Mickey Mouse extensions of his personal works?

The so-called 'Disney Universe' (Wasko, 2001: 3) has become a popular object of scrutiny in cultural studies, though its existence is yet under discussion. Macroperspectives, such as cultural approaches, frequently perform analyses of multiauthorial and heterogeneous discourse, which is perfectly plausible though it falls short of narrative analysis. In this sense, narrative approaches have shown how the classical definition of singular authorship can be applied to transmedia narratives such as big blockbuster franchises (Hernández-Pérez \& Ferreras-Rodríguez, 2014: 49). However, gaining definition as the same narrative act means that together they make up one coherent macro-tale, which requires shared basic narrative elements such as character or spatial settings. While the classical distinction between 'form' and 'content' remains an assumption, there must be some identification of the context in order to talk about 
'author intention'. Without a single author or a clear narrative agenda, it is difficult to bring up 'ethos' (essentially equivalent to author intention).

In response to this challenging question, one could argue that definitions of authorship can be narrowed to mere stylistic features. If authorship is an exercise of style, it may survive the author. In that sense, 'Disney' is no longer only Walt Disney himself but simply another way of understanding cinema. 'Disney' may just be the disembodied essence of an author. It has become, by virtue of distillation or sublimation, a category in its own right. 'Disney' is now a mere adjective, whether it evokes a known trademark or a prestigious major studio. Yet despite being an immaterial version of the author, criticism of Disney is unable to avoid the human origin of the work. Both his circumstances and his charisma continue to appear explicitly in studies of his work. Presumably, these are also a part of his ethos as well as the Disney brand. Is it possible to find other cases in which an individual signature becomes an ever-lasting film brand?

Searching for the Japanese 'anti-Disney': Confronting Miyazaki and Disney narratives

Anime (Japanese Animation) arrived in the Western context mainly through television. Low-cost Japanese productions helped fill the schedules of American children's TV 
programming (Poitras, 2008: 48). From TV, modern Japanese popular culture-from here referred to as manganime - began their expansion to other media, climaxing during the first decade of the 21 st century and leaving a footprint that still remains in global popular culture. In contrast, the cinema medium has been rarely considered as a main gateway for cultural invasion. This is surprising if we consider the number of studies that are exclusively focused on filmmakers, compared to the limited attention paid to creators of other Japanese media (manga, video games, etc.).

The reason for this stems from differences between approaches. Western manganime scholarship adopts a cultural approach, studying the phenomena as a global manifestation of themes, narrative and style. In contrast, film scholars often conduct a more particular analysis. Due to the relevance of author theories, it is not surprising that many of these studies have adopted what we could consider an international and comparative version of auteurism.

This comparison may also be due to a superficial understanding of the Walt Disney legacy. Walt Disney was a very specific type of author-producer, and he cannot be easily compared with other authors. However, since the first anime arrived to Western audiences, many Japanese filmmakers have been compared to Disney. This can be explained by the popularity of the American filmmaker, who is considered synonymous with the medium, but it is also a consequence of the 'doom of the animation', its 
popular designation as a child-oriented medium as with Walt Disney's most popular creations.

In Japan, where the visual arts have been profusely developed for centuries, animation has evolved into a major industry. It synergises with manga (comic book) and other peripheral industries such as the manufacture of toys and video games. Japanese media industries have largely modelled themselves on the Disney corporation due to its successful combination of transnational and transmedia strategies. Here, a natural and obvious comparison has been with Osamu Tezuka (1928-1989), arguably the most influential creator of the manga and anime media. Understanding Osamu Tezuka's figure is key in the articulation of the anti-Disney construction. Tezuka was seriously inspired and influenced by Walt Disney, as well as by other American animators, due to the appeal of their narratives and sophisticated technique (Kelts, 2006:42). While profoundly admired, Tezuka's legacy has also been target of several critics. Tezuka's first TV animations such as Astroboy (1963) were responsible for the implementation of low-budget animation production systems and also elicited the creation of toy-based industries. Towards this father of Japanese animation, it is not strange that Miyazaki himself has contributed to some revisionism:

Just as Tezuka-san couldn't escape Disney's spell while respecting Disney, I too am mired in the spell of Tezuka-san for drawing and director Akira Kurosawa for filmmaking. But I am hopeful that the next generation will break that spell (Miyazaki, 2014a: 71-72). 
This aim to 'killing the father' (in a Freudian sense) has established the equivalence Disney-Tezuka as well as the opposition Disney-Miyazaki. However, Disney productions inspired Asian animation industries for many years before Tezuka's first works of animation ( $\mathrm{Hu}, 2010:$ 59-76). In fact, the first Japanese animation feature film The Legend of the White Snake (1958), made by Toei-Doga, was conceived and promoted as a way to expose Eastern audiences (mainly Chinese and Japanese) to the technical quality achieved by Disney's productions (ibid. 91). More than a decade after the first TV anime, two of the most important figures in Japanese animation history began working in that very same studio: Isao Takahata (1935) and Hayao Miyazaki (1941). Their role as authors, though significant in itself, may be secondary in comparison to their roles as the main anime pioneers in the international market.

Miyazaki (1941) gained success among international audiences and is the better known of the two, and as a result, his work has been more frequently attached to auteurism theories, as the subject of several analyses from this unique perspective (McCarthy, 1999; Napier, 2001; Hu, 2010). As with Disney, Miyazaki's biography has been the main tool for the Western critical reading of his work. Moreover, in the case of this author, a persona or 'mask' has been crafted for him that resembles other forms of authorial mythic criticism (Bordwell, 1988: 27). This mask is equivalent to the construction of the 'anti-Disney', and its development can be analysed via the same 
frameworks used for a critical reading of the American author. Moreover, the ways in which this 'anti-Disney' adjective (along with other forms such as 'Japanese Disney') has been deconstructed helps in understanding the role that biographical and personal traits have played in the construction of Disney criticism.

\section{Ideology and moral approaches}

The assumption of an ideology derived from the major studios's production system is a constant throughout Disney criticism. There is a tendency to extrapolate cultural and ideological conclusions from the analysis of texts. With this, it is assumed a notion of agency as this corporation 'consistently and intentionally selects themes in its commodities-as-animated features that promote an ideology useful to Disney and capitalist society' (Artz, 2004:16). This cultural criticism model of analysis is widespread, extended in all critical schools and traceable back to the first works on 'cultural industries'. Moreover, its influence is still perceptible in film studies and other 'non-academic' paratexts such as newspapers, magazines, monographic books and fandom.

For these authors, Disney's narratives represent the bourgeois world, and meanings around the psychological consequences of capital accumulation are constructed through them. In this case, these messages link directly to the needs of the individual over those 
of society. A common belief is that Disney products create a fantasy world where 'the tertiary sector of economic activity is used ideologically as a utopia, a sentimental projection, as the only future [...]' (Dorfman, et al. 1975: 134). We must note how some of these studies focus on a specific textual corpus. One example is the Disney children's comic book, characterised by a profusion of plots centered on 'everyday life'. Moreover, concerns toward 'bourgeois propaganda' also emerge in the criticism of other fantastic products with a fantastical setting. This happens, for example, with scholars' readings of Disney's fairy tales as mirrors of technological, democratic and other elements of the modern world (Zipes, 1995: 33). This cultural criticism adopts an extremely wide focus and notably falls into overgeneralization, extending this reading to all types of Disney products, from films to merchandising.

In parallel with the aforementioned ideological readings, the message of innocence attached to Disney products is constantly questioned. Here the interpretation is unmistakably ethical, as these positive messages are often contrasted with the harsh reality of malicious global market practices. It is impossible not to consider the relevance of the personal narratives to this criticism. The kindly character of Disney products is often contrasted with political and ideological motivations attributed to the corporation. In these commentaries, an 'Uncle Walt' figure is evoked (Artz, 2004), confronting the well-known filmmaker's dedication to the younger audiences with the darker aspects of the capitalism. There is a clear confusion of moral and macro- 
economy, and a certain pleasure in suggesting the irony of these contradictions, that becomes a criticism of his hypocrisy for virtue of this personalization. A common critique points to the company placing its own commercial interest over the welfare of children, by creating in them non-existent needs and contributing to the spread of a ‘culture of consumption'(Giroux \& Pollock, 2011: 89-90) among children. Cognitive effects among adult audiences are also pointed to, as these scholars warn us about the 'infantilization of the audience' (Dorfman et al., 1975: 157), adopting a Marxist approach and suggesting that a pernicious pedagogical effect may not be limited to children's consumption.

Like the Disney case, studies on Hayao Miyazaki's works also adopt classical critical approaches such as Marxism, feminism, and post-structuralism. However, Miyazaki's persona as individual creator seems to have drawn less criticism. A reason for this lies in the alternate meanings generally attributed to the work of the Japanese author, which again cannot be isolated from biographical circumstances. Unlike the American selfmade man model of liberalism, Miyazaki's persona narratives portray a humanist, pacifist, and ecological thinker (reminiscent of the profile of Osamu Tezuka, the other 'Japanese Disney'). Newspapers, magazines, and even fansites have largely contributed to this mythical construction of Miyazaki as auteur. As with other stereotypical Japanese artist figures, Miyazaki's portraits share 'workaholic' and 'introvert' characteristics, usually noting the rarity of personal interviews with him (Miyazaki \& 
Ebert, 1999; Talbot, 2005; Jolin, 2011;). Raised on the tradition of the manga and anime author cult, Miyazaki recognizes his authority in the studio and his incontestable power. As it happened with other masters of animation (and cinema) he has no remorse in defining himself as a 'dictator' (Miyazaki \& Ebert, 1999). His contribution to this auteur portrait is also reflected in his preference for the term 'eiga' (movie) over 'anime' in describing his own work (Miyazaki, 2014a, 2014b). He classifies his own authorial work with a term linked to the cultural highbrow, also explicitly defining himself outside mainstream Japanese anime, which he rejects because of its sexual and violent content. Even so, like many artists, Miyazaki has made some controversial statements, verging on the polemic. For example, after the terrorist attacks at the offices of Charlie Ebdo magazine on Paris, he commented that "I think it's a mistake to caricature the figures venerated by another culture. You shouldn't do it" (Hawkes, 2015).

It is not uncommon to find an image of anti-Americanism associated with Miyazaki, especially after his statements criticising George Bush and the Iraq War, which have been sufficient to elicit multiple pacifist explanations of his films (Akimoto, 2014). Japanese Prime Minister Shinzō Abe has also been a frequent target of his statements; in particular, Miyazaki questions his interest in expanding the role of the Japanese military and seeks an apology for Japan's dark national past during World War II (Brzeski, 2015). 
Unsurprisingly, Miyazaki has introduced himself as communist or left-oriented, and this political ideology is emphasised through his biographic depiction. For example, his attempt to change the hierarchical Japanese animation industry into a more syndicate and collaborative model is notable (McCarthy, 1999: 30). This narrative offers a contrast with the American creator and his reputation as a 'union buster' and active anticommunist (Artz, 2004: 117).

Hayao Miyazaki's persona has evoked many pacifist readings of his films (see as examples Napier, 2005; Schodt, 1996: 279). Even when these interpretations are primarily based on textual analysis, splitting the personal component from the authorial work often seems impossible. Miyazaki is considered a member of the 'atom boys', a generation marked by the war and subsequent American presence in Japan (Kelts, 2006: 35). Likewise, an anti-Americanist reading of his texts has often been linked to his passion for 'European' landscapes and settings. However, it might be a more logical reading to link European inspiration and the escapism evoked by his film's fantastical settings. There is a fascination for old Europe in Miyazaki's films, in a very similar way to that which can be found on classical Disney movies such as Sleeping Beauty (1959) or Robin Hood (1972).

Whether in a purely fantasy setting (Laputa, Castle in the Sky, 1986) or in a portrait closer to surrealism (Totoro, 1988, Spirited Away, 2001), ecological and environmental 
discourses may be the most discussed aspects of Hayao Miyazaki's filmography. In fact, the image of corporative Miyazaki's persona, Studio Ghibli, is closely linked to environmentalism. This can be profusely observed in the films but also in the narratives presented through corporate image, merchandising and even in the studio's own museum (Denison, 2010: 550). Miyazaki's characters often face situations in which humanity has damaged the environment, and they adopt the role of heroes to compensate for it. While the absence of technological progress is never suggested, a utopian progress based on technological and environmental compatibility is proposed. This is exemplified through the covenant and dialogue between the agents of the conflict—nature and humanity—which is literally translated into a 'ceasefire' in stories of an epic nature (Nausicä̈ of the Valley of the Wind, Princess Mononoke).

There is a double reading behind Miyazaki's epic narratives discourse. On one hand, this may be rooted in religious discourses, as respect for nature is also part of Buddhist and Shinto dogmas. On the other hand, Miyazaki seems to move the premise from ecological issues to 'responsible consumption', which necessarily has certain political connotations. This may refer to the Shōwa period (1960-1980) and its rapid and definitive transformation of Japan into an industrial superpower (Lim Tai Wei, 2013).

The political and ideological significance of Miyazaki's films appears to be consensual. Both a moral and pedagogical tone behind his narratives has been explicitly described 
by the author when he reflects on his work. Even in the darkest passages of his narratives, he prefers not to hide crude or difficult scenes because of the underlying lesson (Miyazaki, 2014:30):

That is what I want elementary school children to see. Kindergarteners may cry at the brutal scenes. Since those scenes deal with problems of life and death, I really wanted to depict them so they could be understood just as they are.

The author consciously addresses his films to young adults and children and appeals to their singular point of view: "I think children have an instinctive perception of the problems of our time, of the problems that lie beneath the surface like a bass harmony" (ibid. 28).

These arguments may be reinforced through the prevalence of other tropes from Japanese folklore and mythology, which are related to his commitment to the rescue of Japanese identity. In this sense, the author shares a vision with other main figures of Studio Ghibli. Acknowledged as the other great auteur of Ghibli, Isao Takahata (1935) has explained his attempt to recover traditional Japanese values by linking his own movies to the long tradition of Japanese visual arts (Koyama-Richard, 2007: 229). 


\section{Gender and Multicultural Discourses}

Representations of gender and race may be easily the most frequent criticisms of Disney's work (Bell et al., 1995; Towbin et al., 2003). A predilection for certain archetypes is commonly pointed out, such as the 'teenage heroine', the 'wicked stepmother' and her nemesis, the kindly 'fairy grandmother' (Bell, 1995: 120-122). While readings of these narrative patterns have more to do with cultural and historical circumstances, many current interpretations tend to focus on the representation of patriarchal power or the perpetuation of traditional family models. These culturally oriented criticisms do not deny the influence of classical literature such as fairy tales in the reuse of these archetypes (ibid: 21 ), yet the textual analysis is incorporated only when it conveniently fits with the discourse. Thus, according to these studies, there is an intimate relationship between traditional themes and the portrayal of stereotypical gender roles. The incorporation of non-stereotypical elements is only noted for the way in which they diverge from the 'classical' narrative. In this way, the evolution of female figures with progressively incorporated masculine characteristics can be accomplished without losing their femininity (England, Descartes, \& Collier-Meek, 2011: 566). Once again, the Disney brand is used to represent an ongoing personal style, as if Walt Disney himself would have approved the script of any modern princess film. 
Miyazaki's characters have also been the objects of study, though they are usually considered a more positive model. Compared with Disney's Pocahontas (1997), for example, Miyazaki's Princess Mononoke has been designated a true attempt to construct a genuine 'national identity' (Yoshida, 2011). In the latter, the main character is a descendant of the Ainu, an ethnic group that is presented with a nostalgic and romantic aura and whose fate is extinction. This is not a central issue in the narrative, so considering the movie, as historical ethnic portrait may not be the best approach. Even when a mythological and religious background has the potential for constructing a national narrative (ibid.), this interpretation is due more to our previous knowledge of Miyazaki's background and Japan than any analysis derived from text. As Napier (2005: 152) points out, Miyazaki's 'memorable female characters' may be the most distinctive elements of his narratives. Generally, young girls are strong, independent heroines who do not avoid action but still condemn violence. With the implementation of these archetypes, Miyazaki defies the conventions of mainstream television anime genres. Unlike other anime that feature light sexual content (so-called 'fan service') that is aimed at shōnen (young male) audiences, Ghibli's female characters are not eroticized and seldom are involved in romantic relationships. These characters are a contrast to the poor depiction of young female psychology in the shojo genre and their common 'identity confusion' problems (ibid). However, although the pattern of the author is original and well defined, it may not be unique, as it can be related to other 
authors' discourses. Ribon no Kishi (1953), a Tezuka manga, first introduced this depiction of female action heroines. This iconic series, later adapted to a well-known and international distributed anime (Princess Knight), may be accredited as the first version of this archetype in the industry.

\section{Structural criticism and Stylistic signatures: the search for uniqueness}

As has been shown, isolating the narrative component from other dimensions of author theories may be challenging. Gender portrayals, the moral tone of the plot, or historical revisionism are issues linked to a particular way of narrating. However, there are some examples of analysis that can be considered as primarily structural or narrative-driven. In fact, the first important analysis of Disney's works praised his style and form (Leyda \& Eisenstein, 1986).

There are still some trends of that school extant in recent analyses of hyperrealism as a distinctive sign of the modernist age (Leslie, 2002; Telotte, 2008). This aspect may be one of the most similar appreciations found in both Miyazaki and Disney criticism, where the textual analysis is less influenced by cultural criticism. Thus, examples of decoupage and mise-en-scène analysis, so common in film studies tradition, can be found in Miyazaki style studies (Moist \& Bartholow, 2007; Ellis, 2010; Kohara \& Niimi, 2013). These studies have contributed to anime auteur theory in two different 
ways. Firstly, they have established Miyazaki's narrative and style as another benchmark in animation standards (Bigelow, 2009; LaMarre, 2002). Secondly, through the comparative study of Miyazaki's authorship patterns, they have incorporated several more names to the 'author anime pantheon', such as Mamoru Oshii, Katsuhiro Otomo and Satoshi Kon.

Other narrative analysis forms focus on the exploration of deep structures. For example, that Disney animated classic movies tend to exhibit an excessive 'homogenization of narrative structures' is a prominent criticism (Pallant, 2010). These observations are reminiscent of others, based on Adaptation Studies, which discuss popular narratives from the perspective of the quality and superiority of their literary sources. In this way, the term 'Disneyfication' has gained prevalence in describing the degradation of more complex narratives (Schickel, 1968: 225; Wells, 2002: 87).

In the case of the Japanese auteur, there is no equivalent case of 'Miyazakification', but the way the author conveys his own unique and personal vision is well recognized. In this sense, Hayao Miyazaki has also shown a predilection for a limited number of narrative tropes. Many of them are widely known, such as the archetypal female heroine previously mentioned, the use of aeroplanes to depict sophisticated movement, or the metaphor of a pig to symbolise 'a turning away from society or humanity' (Moist \& Bartholow, 2007: 33). As often happens with Disney criticism, there is a tendency 
toward biographically-driven analysis in Miyazaki's case too. Thus, auteurism approaches contend that every detail of his work can be explained by its relationship with his past. In Nausica ä of the Valley of the Wind (1984), the main narrative elements are interpreted by critics in a biographical tone: as examples, the use of insects as a result of a pastime of his youth, or the apocalyptic setting as a clear reminder of his experiences related to the nuclear attacks on Japan and their consequences (Schodt, 1996: 278-279).

Miyazaki's work has a large component of adaptation throoughout his filmography, usually from literary sources. The homage to children's literature can be observed even in his most original works. For example, My Neighbor Totoro (1988) was inspired by Japanese mythology. The plot reads as a story of maturation in which imaginary beings from the forest play a transitional role as teachers, and eventually disappear after fulfilling their narrative function. Traces of other children's literature can also be found, whether they are mythological or simply representations of the human psyche, as in Where the Wild Things Are (1963) by Maurice Sendak. What remarkable in the case of Miyazaki is how the use of literary sources has never handicapped the author's agency, unlike in the Disney case. Despite obvious similarities to the original, the new version has been enhanced. This is the case in Howl's Moving Castle (2004). Roughly based on a novel by Diana Wynne Jones, it tends to be viewed as a fairly benevolent treatment of 
the original, as an alternative reading of the original text or as high-quality 'fan fiction' (Levi, 2008: 261).

The 'anti-Disney' as a mythical reinvention of auteurism

Thus far we have reviewed an application of the theory of auteur in the field of animation and the role that Walt Disney's figure has played in the study of animation authorship. Disney is considered the ultimate producer, the creator of a trademark, and finally as synonymous with mainstream conventions. Disney products have been approached as a brand, with the consequence that their meanings and style have reached overgeneralization, without a clear differentiation based on period, media or genre of the case studies. Author theories need to be redefined to address this and other cases of corporative authorship. As Paul Wells (2002: 86) suggests:

[...] this is a tendency to view 'Disney' - the man, the studio, the brand'as an institutional structure which operates as a pre-condition to the film, suggesting that an audience may already 'know' the film, without having wholly 'read' it.

Here we find the most abstract and general form of the adjective 'Disney'. This form transcends the field of textual analysis to accommodate cultural and even philosophical meanings. As an example, Bryman (1999:25) speaks of 'Disneyization' establishing an 
explicit parallel with the popular Ritzer's (1983) 'McDonaldization' concept. Bryman's thesis asserts that society, either in global terms or perhaps for the West only, moves towards a consumer culture similar to that described by other postmodern thinkers like Baudrillard, Bauman or Jameson. His thesis describes the progressive implantation of a model predicated on four aspects: theming, dedifferentiation of consumption, merchandising, and emotional labour - all present in a typical Disney theme park. The term, however, could not be considered a proper form of film criticism because the analysed text-the theme park-is discussed at a metaphorical level. It would, therefore, be a work of a more holistic nature, where the case study is not the work of a particular author but of society itself. Similarities with other forms of criticism are evident, but not only in comparison to other ethical readings of Disney texts. Examples include text effects, similar to the 'infantilization of the audience' discussed earlier. However, consequences should be considered neither psychological nor pedagogical but related to a sociological approach, as they primarily affect social institutions. The author's work transcends its narrative properties and acquires a real ability to shape the audience, producing ongoing ripples in society.

Decades after Disney's death, his name and style remain the benchmark of quality for other animation producers. However, in contrast to the Disney narratives, the works of other authors are often addressed as personal art with meanings that are not of a hegemonic but of a subversive nature. Miyazaki's work is an example of this, because it 
is always - either consciously or unconsciously — decoded in terms of the 'auteur'; in this interpretation, the comparison with Disney seems to be a recurring and intentional strategy in order to reinforce other implicit aspects of this anti-Disney mask.

Firstly, there is a mythical approach to the author. Narrative about the author contributes to ideological readings and these have as a consequence the ethical criticism of his narratives. Conversely, stories of the anti-Disney usually depict a serious, introverted, and hardworking man. In some ways this image of the author seems to fit with the image of other 'true artists' in presenting the author in a morally transcendent dimension: his work is a form of selfimprovement and character building.

Secondly, as has been widely addressed (Grant, 2000: 101), through a postmodern conception of authorship, the concept of 'auteur' is justified not by the identification of personal authorship but by its construction of the authorial image and its discovery through paratexts (interviews, film critics, making of documentaries, etc.). The case of Disney is unique as there are a number of relevant works about his life and legacy. Though the amount and complexity of Walt Disney cultural production since the creation of the major production house makes it impossible to limit its analysis to film phenomena. In the case of Miyazaki, it is clear that film criticism has contributed to the pleasure of 'discovery' in the audience-Roger Ebert, a celebrated film critic, called 
him 'The greatest animator alive' - though it cannot be denied that the Japanese master is a cult figure with anime fan audiences all over the world.

Closely related to this idea of the complex creative personality are textual analyses that are generally constructed with a biographical tone and also exhibit a tendency toward Orientalism (in opposition with Disney). As with the rhetoric of nihonjinron (Iwabuchi, 2004: 49-50), the singularity of the Japanese spirit is the centre of a discourse surrounding a number of Japanese literary and narrative tropes. However, film criticism diverges from manga and anime studies on this topic. For academics, many of the facets that critics consider idiosyncratic to Miyazaki may be due to a lack of understanding of the Japanese cultural background. The problem with this is that a purely cultural analysis of the national character of an artistic signature would eventually undermine the notion of 'authorship' itself. It also creates a parallel problem of defining the relationship between cultural background and textual analysis. For example, $\mathrm{Hu}(2008$ : 4) points to a contradiction in Napier (2001: 47), in how the author appeals to the Japanese or Western narrative features of Miyazaki according to convenience. Opening a discussion of Japanese animation films' cross-cultural reading is beyond the scope of this essay, but the auteur theory does not exclude other theoretical frameworks. Regardless of the importance of authorship in film analysis, it is clear that authors exist and that they have an important role in the promotion and critical reception of a film. 
Miyazaki's signature is undeniable, coherent and recognizable. However, it would be a mistake to understand anti-Disney discourse as purely antithetical to Disney criticism. Again, the anti-Disney is only one way to analyse an author, as a label that incorporates many other labels ('The Japanese Disney', 'the Disney from Asia', etc.). Despite the many differences originating from ideological and biographical readings, there are still similarities: primarily, the underlying qualities of their productions as well as the reverential consumption of their works by all manner of audiences. In that sense, the great authors in the world of animation may all fit the definition of 'Disneyan', as it works as a metonym for an authorial, complex, hierarchical industrial process that organizes and executes selective practices within the vocabularies of animated film (Wells, 2002).

It should not be surprising, perhaps, that Disney and Miyazaki corporations formed an alliance. In 1996, the Disney-Tokuma deal allowed the distribution of many Studio Ghibli films in the Western market for the first time. While some critics claimed that Miyazaki 'had sold his soul', the agreement brought great benefits to the Japanese company, including the opening of a sizeable new market while keeping the integrity of the work shielded against possible censure or adaptations (McCarthy, 1999:48).

It is clear that Ghibli corporation has achieved a considerable economic and cultural success by following strategies similar to those of the Disney brand. Since 2001, Ghibli 
has even established its own museum, which has been considered 'Miyazakiland' (Cavallaro, 2006: 43). In fact, the term may be very appropriate, as the museum is designed not only around the company films' narrative but also around the cult of Miyazaki's figure and his personal philosophy, which may be considered the most important capital for the company. While the brand Disney may be universally associated with ideas like 'animation quality' or 'familiar entertainment', Ghibli films may experience a different reception with Japanese and international audiences. In Western countries, Ghibli owe its prestige to the accredited 'independence' and 'singularity' of its filmmakers, but in Japan the brand is especially appreciated for its 'traditional' and 'handmade' values that remain the way that (pre-digital) Disney films were once perceived.

If one uses the term 'Disneyzation', it would seem that 'Miyazafication' is an equally valid phenomenon. This would imply accepting a discourse of authorship that is based on the creation of a brand that originated from an individual style. Miyazaki is not the only filmmaker working for the studio and his visual style is common to other Ghibli animators. Moreover, producers cannot be considered creators themselves, but but contribute actively to the creation of a 'brand style' (Bernstein, 2008:188). This is true for Toshio Suzuki (1948), former president of Studio Ghibli. While not as popular as Ghibli's filmmakers, Suzuki is a well-known figure who participated actively in promotional paratexts as well as in documentaries and interviews (most notably the 
documentary movie The Kingdom of Dreams and Madness, 2013). His work has been pivotal in the development of the main Ghibli blockbusters, and he also played a major role in promotion as editor of Animage (1978-), the official magazine of the studio and a main channel of the auteur's insights.

The Studio Ghibli signature is present not only in films but also in other products that feature major thematic tropes from Miyazaki films, including Ghibli museum's exclusive short films, video games and other merchandising products. Studio Ghibli has produced several commercials, offering in its delicate hand drawing an amalgam of traditional and family values that have attracted relevant Japanese companies as customers. This is the case for the corporate video made for Marubeni Group, Making someone in the world happy (2016), based on the 12th Century "Choju-jinbutsu-giga" (Scrolls of Frolicking Animals and Humans). In a similar vein is Taiko no Tasujin (2015) directed by Toshio Suzuki (1948) for Bandai Namco. The style of both works explicitly refers to traditional Japanese visual arts in a very similar way to other major productions, such as the last work of Takahata: The Tale of Princess Kaguya (2013).

However, cultural criticism would produce irregular results. A new generation of directors may have replicated style guidelines, but they seem to have their own identity (and reputation) as narrators. This is the case of Hiromasa Yonebayashi (1973) and the son of the main figure of the studio, Gorō Miyazaki (1967). Despite their great 
commercial success, they have also been received with different critical enthusiasm than other creators at Studio Ghibli.

Following the announcement of Hayao Miyazaki's retirement, Studio Ghibli began to gradually change its commercial strategy. In August 2014, the studio announced the dismantling of the production department in the middle of the promotion of When Marnie was there (2014), the studio's latest film (Ponsford, 2014). Some months later, the study announced the coproduction of "The Red Turtle" (2016), first Ghibli film not directed by a Japanese director (ANN, 2015).

It may be possible to talk about a certain Ghibli corporative style but it is unclear whether this may be carried to the extent of the 'authorship after death' that has frequently been assumed in Disney's film legacy. Miyazaki himself avoids answering the open question about the company's future asserting that " 'Ghibli' is just a random name (...), It's only a name" (Ponsford, 2014).

Only the future will reveal what will happen to Studio main auteur, and, if 'Miyazaki' as a noun will be degraded to a mere adjective.

\section{Conclusions}

This research has shown how the term 'author' should be redefined to provide better understanding of the current context of global audio-visual production. Transmedia 
authorship, film branding phenomena and the creation of unique corporative visual styles offer new and yet unanswered challenges to media studies. In this sense, scholars' assertions that auteur theory should be a tool rather than an object of knowledge are valid (Caughie, 2008: 410).

Anime scholarship may be still in the early phase of self-definition; it is the first part of a process, establishing a main foundation for its particular pantheon. Limiting the authorship study to these limited but basic pieces may impede the development of the entire construction. In the future, it may be possible that 'anime' scholarship will move beyond cross-cultural readings particular to Miyazaki. It may be possible to find new and singular auteurs, and with a better knowledge of global industries, their individual stylistic signatures may be isolated from brand styles and genre traditions. In short, a place for true 'author theory' remains, and so do its applications in Japanese animation and by extension, in the animation medium itself.

\section{References}

Anime News Network. (2016) Studio Ghibli Co-Produced Film The Red Turtle to Screen at Cannes. News Archive. Available at: http://www.animenewsnetwork.com/news/2016-04-15/studio-ghibli-coproduced-film-the-red-turtle-to-screen-at-cannes/.101089 (accessed 15th April, 2016).

Artz L. (2004) The righteousness of self-centred royals: The world according to Disney 
animation. Critical Arts 1(18): 116-146.

Anderson K and Anderson PF. (2005) Ken Anderson by Paul F. Anderson. In: Ghez D (ed) Walt's People - Volume 1. Talking Disney with the Artists who Knew Him. Bloomington (Indiana, US): Xlibris, 102-122.

Akimoto D. (2014) Howl's Moving Castle in the War on Terror. A Transformative Analysis of the Iraq War and Japan's Response. Electronic Journal of Contemporary Japanese Studies 2(14).

Bell E, Haas L and Sells L. (1995) From Mouse to Mermaid: The Politics of Film, Gender and Culture, Bloomington: Indiana University Press.

Bernstein M. (2008) The producer as auteur. Auteurs and Authorship: A Film Reader. Maldwell, MA: Blackwell Publishing, 180-189.

Bigelow SJ. (2009) Technologies of perception: Miyazaki in theory and practice. Animation. An Interdisciplinary Journal 1(4): 55-75.

Bordwell D. (1988) The classical Hollywood Style, 1917-60. In: Bordwell D, Staiger J and Thompson K (eds) The Classical Hollywood Cinema: Film Style \& Mode of Production to 1960. New York: Routledge, 1-87.

Bryman A. (1999) The Disneyization of society. The Sociological Review 1(47): 25-47.

Brzeski P. (2015) Hayao Miyazaki Slams Japanese Prime Minister, Reveals New Animation Project. The Hollywood Reporter. Available at: http://www.hollywoodreporter.com/news/hayao-miyazaki-slams-primeminister-808266. (accessed 15th June 2016).

Carringer RL. (2001) Collaboration and Concepts of Authorship. Publications of the Modern Language Association of America): 370-379.

Caughie J. (2008) Authors and auteurs: the uses of theory. In: Donald J and Renov M (eds) Handbook of Film Studies. London: Sage, 408-423.

Cavallaro D. (2006) The animé art of Hayao Miyazaki, Jefferson: McFarland.

De la Merced MJ. (2012) With Lucasfilm Deal, Disney Spends Big to Land a Lucrative Franchise. DealB\%k. Available at: http://dealbook.nytimes.com/2012/10/30/with-lucasfilm-deal-disney-spends-bigto-land-a-lucrative-franchise/ (accessed 30th May, 2016). 
Denison R. (2010) Anime tourism: discursive construction and reception of the Studio Ghibli Art Museum. Japan Forum, 22.

Dorfman A, Mattelart A, Kunzle D, et al. (1975) How to read Donald Duck: Imperialist ideology in the Disney comic: International General New York.

Ellis J. (2010) The art of anime: Freeze-frames and moving pictures in Miyazaki Hayao's Kiki's Delivery Service. Journal of Japanese \& Korean Cinema 1(2): 21-34.

England DE, Descartes L and Collier-Meek MA. (2011) Gender Role Portrayal and the Disney Princesses. Sex Roles 64: 555-567.

Giroux HA and Pollock G. (2011) Is Disney good for your kids? How corporate media shape youth identity in the Digital Age. In: Steinberg SR (ed) KINDERCULTURE. The Corporate Construction of Childhood. Boulder: Westview Press.

Grant C. (2000) www.auteur.com? Screen 1(41): 101-108.

Hawkes R. (2015) Hayao Miyazaki: Charlie Hebdo Mohammed cartoons were 'a mistake'. The Telegraph. Available at: http://www.telegraph.co.uk/culture/film/film-news/11417395/Hayao-MiyazakiCharlie-Hebdo-Mohammed-cartoons-were-a-mistake.html (accessed 15th June 2016).

Hayward S. (2013) Auteur/Auteur Theory/Politique des Auteurs/Cahiers du Cinéma. Cinema studies: the key concepts. Routledge, 27-34.

Hernández-Pérez M and Ferreras Rodríguez JG. (2014) Serial narrative, intertextuality and the role of audiences in the creation of a franchise. An analysis of the Indiana Jones saga from a cross-media perspective. Mass Communication and Society 1(17): 26-53.

Hu T-yG. (2010) Frames of anime: culture and image-building, Hong Kong: Hong Kong University Press.

Iwabuchi K. (1994) Complicit exoticism: Japan and its other. Continuum: Journal of Media \& Cultural Studies 2(8): 49-82.

Jolin D. (2011) Miyazaki On Miyazaki: The Animation Genius On His Movies. Empire 
On Line. Available at: http://www.empireonline.com/movies/features/hayaomiyazaki/ (accessed 16th June 2016).

Kelts R. (2006) Japanamerica: How Japanese pop culture has invaded the US, New York: Palgrave Macmillan.

Kohara I and Niimi R. (2013) The Shot Length Styles of Miyazaki, Oshii, and Hosoda: A Quantitative Analysis. Animation. An Interdisciplinary Journal 2(8): 163-184.

Koyama-Richard B. (2007) One Thousand Years of Manga Paris: Flammarion.

Lamarre T. (2002) From animation to anime: drawing movements and moving drawings. Japan Forum 2(14): 329-367.

Leslie E. (2002) Hollywood flatlands: animation, critical theory and the avant-garde, New York: Verso.

Levi A. (2008) Howl's Moving Castle. Mechademia (3): 261-263.

Leyda J and Eisenstein S. (1986) Eisenstein on Disney: Seagull Books Pvt Ltd.

Lim TW. (2013) Spirited Away: Conceptualizing a Film-Based Case Study through Comparative Narratives of Japanese Ecological and Environmental Discourses. Animation. An Interdisciplinary Journal 2(8): 149-162.

Martinez OOL. (2015) Criteria for Defining Animation: A Revision of the Definition of Animation in the Advent of Digital Moving Images. Animation. An Interdisciplinary Journal 1(10): 45-57.

McCarthy H. (1999) Hayao Miyazaki: master of Japanese animation: films, themes, artistry, Berkeley: Stone Bridge Press.

Miyazaki H. (2014) Starting Point: 1979-1996, San Francisco: Viz Media.

Miyazaki H. (2014) Turning Point 1997-2008, San Francisco: Viz Media.

Miyazaki H and Eberet R. (1999) Director Miyazaki draws American attention. Rogereberet.com. Available at: http://www.rogerebert.com/interviews/directormiyazaki-draws-american-attention (Accessed 15th June, 2016).

Moist KM and Bartholow M. (2007) When Pigs Fly: Anime, Auteurism, and Miyazaki's Porco Rosso. Animation: An Interdisciplinary Journal 1(2): 27-42. 
Napier SJ. (2001) Confronting master narratives: History as vision in Miyazaki Hayao's cinema of de-assurance. Positions: east asia cultures critique 2(9): 467-493.

Napier SJ. (2005) Anime from Akira to Howl's Moving Castle: experiencing contemporary Japanese animation, New York: Palgrave Macmillan.

Pallant C. (2010) Disney-Formalism: Rethinking 'Classic Disney'. Animation: An Interdisciplinary Journal 5: 341-352.

Poitras G. (2008) Contemporary Anime in Japanese Pop Culture. Japanese visual culture: explorations in the world of manga and anime. 48-.

Ponsford M. (2014) The death of Studio Ghibli was inevitable — but this might not be the end. Independent.co.uk. Available at: http://www.independent.co.uk/voices/comment/the-death-of-studio-ghibli-wasinevitable-but-this-might-not-be-the-end-9649853.html (Accessed 15th June, 2016).

Ritzer G. (1983) The "McDonaldization" of society. Journal of American Culture 1(6): 100-107.

Rohmer E and Chabrol C. (1979) Hitchcock, the first forty-four films, New York: Frederick Ungar.

Sarris A. (1963) The auteur theory and the perils of Pauline. Film Quarterly 4(16): 2633.

Schickel R. (1968) The Disney version: The life, times, art, and commerce of Walt Disney, New York: Simon and Schuster

Schodt FL. (1996) Dreamland Japan: Writings on Modern Manga, Berkeley (California): Stone Bridge Press.

Talbot M. (2005) The Auteur of Anime. Japan Focus: The Asia-Pacific Journal 3(4.

Telotte J. (2008) The Stereoscopic Mickey: Space, Animation, and the Mouse. Journal of Popular Film and Television 3(36): 133-140.

The Walt Disney Company. (2015) The Walt Disney Company Reports Fourth Quarter and Full Year Earnings for Fiscal 2015. Available at: https://thewaltdisneycompany.com/the-walt-disney-company-reports-fourthquarter-and-full-year-earnings-for-fiscal-2015-2/ (Accessed 15th June, 2016). 
Towbin MA, Haddock SA, Schindler Zimmermann T, et al. (2003) Images of Gender, Race, Age, and Sexual Orientation in Disney Feature-Length Animated Films. Journal of Feminist Family Therapy 4(15): 19-44.

Wasko J. (2001) Understanding Disney: The Manufacture of Fantasy, Cambridge: Polity Press.

Wells P. (2002) Animation. Genre and authorship, London \& New York: Wallflower.

Yoshida K. (2011) National Identity Construction in Japanese and American Animated Film. Self and Other Representation in Pocahontas and Princess Mononoke. Electronic Journal of Contemporary Japanese Studies 5.

Zipes J. (1995) Breaking the Disney Spell. In: Bell E, Haas L and Sells L (eds) From Mouse to Mermaid: The Politics of Film, Gender and Culture. Bloomington: Indiana University Press, 21-42. 